\title{
Dissonant Doppelganger: Performing the Post-Natural Through MODULATED FOLEY TECHNIQUES
}

\author{
Mark Peter Wright \& Angus Carlyle ${ }^{1}$ \\ University of the Arts, London
}

This mixed media contribution investigates the multiple modes of inscription possible within a practice-based investigation of the Sonic Anthropocene. Drawing upon critical contexts from Geology, Geography and Anthropology, and the relations between writing, bodies and earthly matters, the authors suggest a re-writing occurs in mediated acts such as field recording (phonography). Microphonic translations from the field not only re-inscribe sites, plural; they reveal sound's itinerant nature to be full of duplicitous and fictive potential. Operating such possibility through the practice of Foley, the post production art of material based sound effects, the authors pivot discussions around their soundwork Decoys (2018) and its attempt to address the urgency of anthropogenic change through a latticing of source and signal, site and studio, subject and observer, human and more-than-human.

Keywords: decoys, environmental fiction, foley, inscription, sonic anthropocene

In Dipesh Chakrabarty's 2018 essay “Anthropocene Time," he amplifies a terminological tone in the conceptual formation of the Anthropocene. The vibrations of definitional language are perhaps most palpable in the pressures that have accumulated around the official designation of the nomenclature itself, yet there are tangible tremors both in the past philologies for that expression (Chakrabarty hears the term echoing from the nineteenth century) just as there are rumblings in contemporary counter-coinings (which he illustrates with respect to the neologism "Capitalocene" that many associate with Donna Haraway but for which Chakrabarty finds a least two alternative genealogies). Kathryn Yusoff's A Billion Black Anthropocenes or None (2018) traces the etymology of geography to "earth-writing," with the discipline's writing creating "material stories [as] origin stories - stories that reproduce not just arrangements

1 Mark Peter Wright is Post-doctoral Researcher based at CRiSAP (Creative Research into Sound Arts Practice), University of the Arts, London. markpeterwright@gmail.com www.markpeterwright.net. Angus Carlyle is a Professor of Sound and Landscape based at CRiSAP (Creative Research into Sound Arts Practice), University of the Arts, London. anguscarlyle@gmail.com, www.anguscarlyle.com 
of matter but subjects through divisions of matter" (2018:19). As material reproductions, the writings of geography - host discipline of the Anthropocene - connect to historical enslavements and subjugations where "Indigenes and Africans become rendered as a writ or ledger of flesh scribed in colonial grammars" (2018: 33). With the "nomination of the Anthropocene" comes a heightened recognition of the political relations between geography and geology, with Yusoff asserting that "the biopolitics of life has a more expansive mineralogical geography that needs attention." In these charged and complex circumstances, the "intermingling of social and natural causality in anthropogenic climate change [produces] the 'renaturalising' of humanity as geologic [...] this new understanding of being as geological (italics in original)" (2013: 780).

\section{EXPANDING THE GRAMMARS OF THE ANTHROPOCENE}

Amitav Ghosh (2016: 11) describes the Anthropocene as a time of Great Derangement, an epoch which celebrates its claims to self-awareness yet remains, in its artistic practices, largely inattentive to the myriad agencies and artefacts that are simultaneously destroying the world. However, Yusoff, in the later sections of her book, points to the possibilities of what might amount to a counter geography, a "re-writing" of the Anthropocene, an "expansion of its grammars" (2018: 18). In this process, inspired by the imperatives of the poetics of Audre Lorde and Édouard Glissant among others, Yusoff unearths an "insurgent geology" (2018: 95) appropriate to a decolonizing Anthropocene in two specific films of Steve McQueen and in the writing of Dionne Brand and of Sylvia Wynter. In part, this insurgency and its re-writings, might interrupt the historical elision between geography and geology that was enacted in the terrors and violence that Glissant evokes so powerfully in the opening passages of Poetics of Relation. For Yusoff, the "superimposition of colonialism was a shearing of subjects from geography and the reinstantiation of those subjects into a category of geology that recoded them as property, whereby extraordinary possibilities in relation to the earth were wiped out" (2018: 41).

Yusoff's sifting for other, more disruptive, grammars can also be heard as an inspiration to short-circuit some of the tropes that coalesce in the visual constitution of the Anthropocene, where disactivated spectators watch time-lapsed glaciers shrinking, see footage of a lonely polar bear circling on grass revealed by the thaw, repeatedly replay those shots of the icebergs calving. Yusoff is attuned to the visual modality through which the Anthropocene is delivered, with the glaciers, bergs and polar perhaps constituting convincing candidates for what she calls the "cathartic images of catastrophe" (2017: np). The opening sentence of her 2017 essay "Epochal Aesthetics: Affectual Infrastructures of the Anthropocene" addresses how the "Anthropocene renders visible new architectures of time and matter" and the passages which follow reverberate with a language of "looking," "vision," "images" and "imaginary." In a particularly resonant phrase, Yusoff summons a "geo-logics of social and material expulsions whose visible effects have been hidden in plain sight all along" (2017: np). Yusoff is not here reinforcing the sensory dichotomy that sound studies scholar Jonathan Sterne calls "the audiovisual litany" which "idealizes hearing (and, by extension, speech) as manifesting a kind of pure interiority. It alternately denigrates and elevates vision: as a fallen sense, vision takes us out of the world. But it also bathes us in the clear light of reason" (2003: 15). For one thing, in "Epochal Aesthetics,"Yusoff (following Berlant) talks of a subterranean excavation from which we might "see how those forces both maintain and disrupt edifices of intention on the surface (our emphasis)" (2017: np). For another, in an argument located in those later sections of $A$ Billion Black Anthropocenes or 
None addressed in the preceding paragraph, Yusoff synthesises Tina Campt's (2018: 98) counterintuitive methodology of listening to images. Campt amplifies the quiet soundings that exist beyond the conventional frame. Her analysis demands a sonic sensibility that unsettles visual codes and mixes sensory feedback in searching beyond the apprehensible. Such an approach blurring rather than supplanting - encourages other forms of engagement. Whether these other engagements are ultimately capable of disrupting the symbolic repertoire which contributes to what Chakrabarty talked of in an earlier essay as "the responses of [...] denial, disconnect and indifference" (2009: 35) is another matter. Nonetheless, the animation of other sensory registers than the visual, without capitulating to the rigorous border patrolling involved in the "audiovisual litany" but involving a more errant blurring instead, feels part of a necessary recalibration of responses simultaneously to the erased past, the deranged historical present and to radical futurities to come.

AM Kanngieser's contribution to GeoHumanities in 2015 had already set these matters into articulate motion when they followed Ursula K. LeGuin's "[call] for a geolinguistics that expands what is considered as language into matter, into the material; an expansion that can be undertaken specifically through the medium of sound [...] I take sound, only in part the utterance, as a geophilosophical provocation to, and a method for, political contestation" Kanngieser (2015: 1). Thus, approaching the Anthropocene through a sonic filter might very well invoke listening as a mode of attention or tuning. The consequence being found in the conceptual and methodological strain towards phenomena that escapes human reach. Confronting such difficulty demands an acceptance of not knowing, of being all at sea in a multisensory and multispecies ocean, one that threatens to subsume so-called knowledge all together.

As a potential exception to the dominant mode of deranged indifference that Ghosh diagnoses in the "art and literature of our time," is the very genre with which LeGuin is associated: science fiction. This may be where "traces and portents" of extreme environmental stress and its imbrication with human histories and oppressions can be found, and certainly science fiction was an inspiration as we were developing the Decoys project. Of course, the mainstream of science fiction may well flow along with Ghosh's indifference, but there are eddies and counter-currents at the edges where science fiction appears turbulent with new significance as a speculative space to explore ecological destruction. This is not exclusively an attribute of the literary science fiction that could be exemplified in the sub-genre of climate fiction ("cli-fi") but finds itself oozing into filmic and artistic channels, or such combinations of the two as might be found in The Otolith Group. ${ }^{2}$

\section{FABRICATING A SONIC ANTHROPOCENE}

We turned to these inspirations in Decoys in order to respond and fabricate narratives towards a Sonic Anthropocene. As part of that process, our collaboration was alert to other conjunctions between grammars and experiences, embrained and embodied. Both of us have long entwined writing within our respective creative practices, vacillating between modes of the fictional and the documentary and we have separately done so in the critical auspices of writing practices associated with anthropology, particularly as it is complexified through Michael 
Taussig's account of the fieldwork diary. For Taussig, that diary is "built upon a sense of failure - $\mathrm{a}$ foreboding sense that the writing is always inadequate to the experience it records. Nevertheless, on rereading by its author, the diary has the potential to bring forth a shadow text that can simulate the experience that gave birth to the diary entry, not only for what is said, but more likely for what is omitted yet exists in gestures between the words" (2011: 100). Anthropology and ethnographic fieldwork teach us that site is a palimpsest of relations. The field is "thickened" beyond neat truth claims through an interpretative chain of perspectives, senses, scales, actors and transcriptions. ${ }^{3}$ Deploying a microphone as our prime interlocutory tool, we move between exteriors and interiors, humans and nonhumans, studio, edit suite, speaker and auditioning ear. A field recording can never be a simple sonic truth due to the chain of events and apparatus, pre and post, required across its scales of audition. The "real" will always unspool in the task of capturing sound and representing place.

Foley art recreates extra-verbal sounds often pertaining to close up movements, animals or objects as well as atmospheres. Bear claws are paper clips attached to gloved fingers. Thunder is a piece of tin foil. Rain is the sound of frying bacon. Such examples are recreated through performance as the Foley artist synchronizes sound to moving image. The work is often performed in a bespoke setting. The field is a soundproofed room optimized for sonic control and fidelity. Foley stages are mutable environments. Floor textures and surfaces can be easily swapped. Everyday objects such as chairs or door handles are detached from context and elevated into performative agents.

In Decoys it is the auditory that we detect between objects, words and visual tropes. And not just an undifferentiated auditory - not sound for its own sake, not a self-sufficient sonorousness - but one that is as keen to relate and disrupt the gestures of Foley practices that conventionally seek to render the Natural. We embarked on a process of investigating and subsequently enacting the operations associated with Foley, the means through which artificial sound effects are created in a studio to enhance the events and atmospheres being conveyed. Foley finds a secure home within televisual and cinematic contexts, but radio and its lesser known museological roots suggest it does not always need to follow visual cues.

The exhibition "Men from Montaña," held at the American Museum of Natural History in 1951 is useful to note here. An example of Foley before film, the exhibit was a typical anthropological inquiry of its time that focused a curatorial Western gaze upon eight Peruvian tribes and their material and cultural practices. The use of media however, was not so conventional as sound was notably employed within the museum setting for the first time. Contrary to marketing that implied site-specific field recordings from the mountains of Peru, sounds were in fact sourced from sites such as the Brooklyn Zoo and produced through Foley techniques recorded in a Manhattan bathtub. ${ }^{4}$ Released on LP under the giveaway title The Sounds of a Tropical Rain Forest in America (1952), the project is a work of sonic fiction free from the demands of a visual lead. In this example, we see the promise and threat of Foley as a productive intervention of sensorial hierarchies, whilst at the same time harbouring a latent potential for appropriative

3 Geertz (1973) claimed meaning becomes "thick" through interpretive layering and analysis that folds context and subjectivity into ethnographic accounts. Rather than transmitting "facts", knowledge is consequently thickened as truth claims move beyond sound bites and authorial hierarchy, and instead entangle the multiple actors, scales, and perspectives operating within the participation and mediation of place or community.

4 For more information on this specific context see Craig Eley, "When it Rains, it Pours," Smithsonian Folkways Magazine, (Fall/Winter, 2012). 
abuse. Foley therefore, has material and epistemic force that operates within and outside the codes of its media historical relations. It is a force that can practically arrive before the image rather than during post production; and it is a force that troubles the meaning-making end of the knowledge chain. Not only does it enact the post-natural, it dilutes what we think we know, sense, and see of the Anthropocene along with its various claims of origin and terminology: the practice-based dance of balancing site-sensitive and situated knowledge is always at stake.

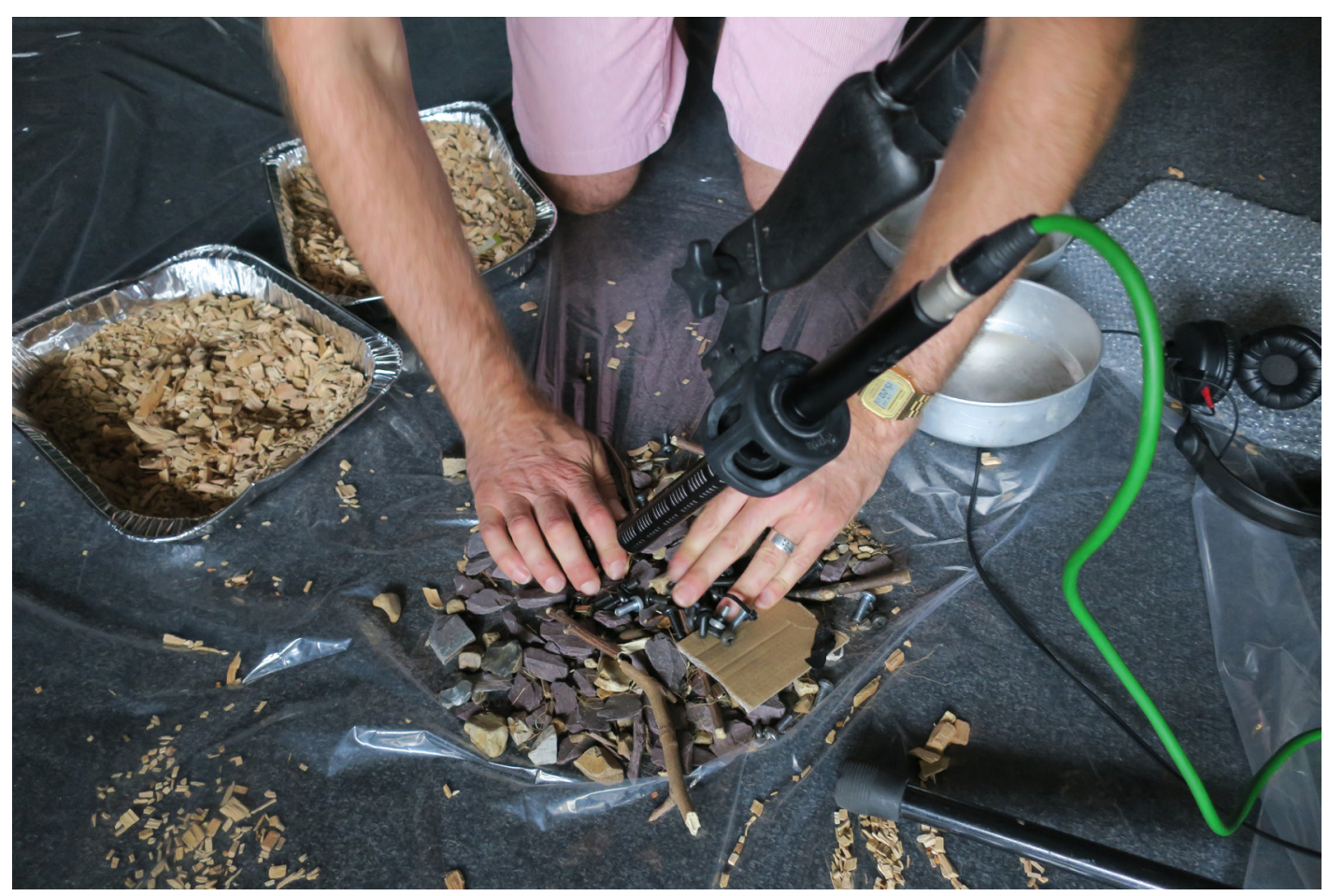

Foley studio work. Credit: Carlyle \& Wright, 2018.

Contemporary modulations of Foley by artists such as Julie Rose Bower, ${ }^{5}$ Lawrence Abu Hamdan $^{6}$ and Maria Chavez ${ }^{7}$ provide a lens that emphasises the socio-political entanglements of sonic materiality. Although some of what "hand-crafted" Foley once provided has since been superceded by the availability of digital sound effects libraries, nonetheless, the practice still persists and remains the subject of popular online tutorials and books such as Foley Grail: The Art of Performing Sound for Film, Games and Animation (2014). If Foley has tended to be associated with drama, the revelatory behind-the-scenes account of sound produced by Earth Touch News Network ${ }^{8}$ demonstrates that its use is more widespread. It was the particular role of Foley within nature documentary that we allowed ourselves to be inspired by in Decoys.

5 Julie Rose Bower's solo performance work "Foley Explosion” (2017) deploys a considerable range of Foley techniques to dramatize a complex narrative and "conjure a movie in the mind."

6 Lawrence Abu Hamdan's works "Earwitness Inventory" (2018) and "After SFX" (2019) explore the intersection of Foley practices and legal testimony, evoking how the objects to be sounded constitute a "collection [that] stands for a language that we do not yet speak, a language of and between objects". http://lawrenceabuhamdan. com/\#/earwitness/

7 Maria Chávez's work "Between A Gunshot and A Whisper" (2017), her contribution to the arts biennale Documenta 14, seeks to connect sound effects to "abstract histories of sonority" https://www.documenta14.de/en/ public-radio/14725/between-a-gunshot-and-a-whisper

8 Earth Touch News Network is a production platform dedicated to "the latest news and emerging stories about the natural world”. For more information see: https://www.earthtouchnews.com/ 


\section{Performing the Post-Natural Through Modulated Foley Techniques}

What if we begin with the fabrication of sound events as a deliberate ethico-aesthetic strategy? How can we deploy sonic doppelgängers that invite critical listening? Can the material and conceptual fabrication of the field speak towards urgent matters of biodiversity loss, extinction and possible futures? What does it mean to produce sound recordings from anthropogenic materials and can a "green" Foley practice emerge in which the objects employed and sounded are sustainably sourced?

Decoys speculates with the sonic post-natura $1^{9}$ and operates the duplicitous potential of Foley art; it sabotages orthodoxies of classical music's program note as a space for science fiction and subverts the instructional score as a deliberately under-resolved, conflictual proposition. Consequently, Decoys iterates further disruption onto field recording praxis. With a synonym for field recording being "phonography" - etymologically the writing of sound - there is a mirroring, albeit at a much-telescoped scale, of the bifurcating processes of inscription that Yusoff identified with geography. For Yusoff, geography's colossal coloniality is what has persisted from slave ledgers to the debates around the Anthropocene, yet there are other grammars that can contribute to a "re-writing" that might produce her insurgent geology. For Kanngeiser, there is a parallel oscillation. Although the "Anthropocene is predicated on exploitation, colonialism, slavery, and genocide [and] by listening to places and spaces, it is possible to discern uneven, often-obscured, and gradual processes, such as extinction and dispossession," (2015:2) by the same token, "by using sound to explore political relations [...] it becomes possible to see how those political relations can help to build new and creative terrains for human and morethan-human negotiations" (2015: 5).

Our own work therefore attempts to unsettle claims of the Universal and Natural that undergird histories of field recording, a discipline that privileges Western-Euro perspectives, propagated by the myth of inconsequential sound capture: it is anything but. The task for us then, and Foley more broadly, is in rendering its potential to delink power and truth, whilst holding onto social political implications: to attend to errant boundary blurrings and generate “epistemic disobedience" (Mignolo, 2009: 160).

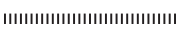

Audio Track

https://archive.org/download/Decoys/Decoys.m4a

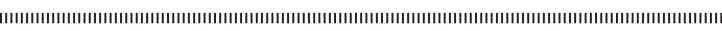

\section{SOUND NOTES}

Decoys was the result of the inaugural commission from the London-based record label multi.modal, a venture established by musicians, artists and researchers Claudia Molitor and Tullis Rennie with the intention of triangulating the "borders between improvisation, field recording and composition." Other than this thematic triangulation and the commitment that

9 The term post-natural situates itself around the collapse of nature culture binaries within Anthropocene discourse. A specific sonic context is located within fields such as acoustic ecology and field recording where nature has long been reified, captured and composed as an object rather than subject of complex agency, power and participation. For more information see: https://www.researchcatalogue.net/view/292319/292320/0/0 
the series of releases that we were to initiate would be manifest as 12" vinyl LPs, multi.modal's invitation was offered to us without any declared imperative. Nonetheless, our respective practices and interests were familiar to Molitor and Rennie through prior encounters and this may have led to them investing certain expectations in our collaboration, expectations which, in a sense, we both encouraged and, ultimately, sought to frustrate.

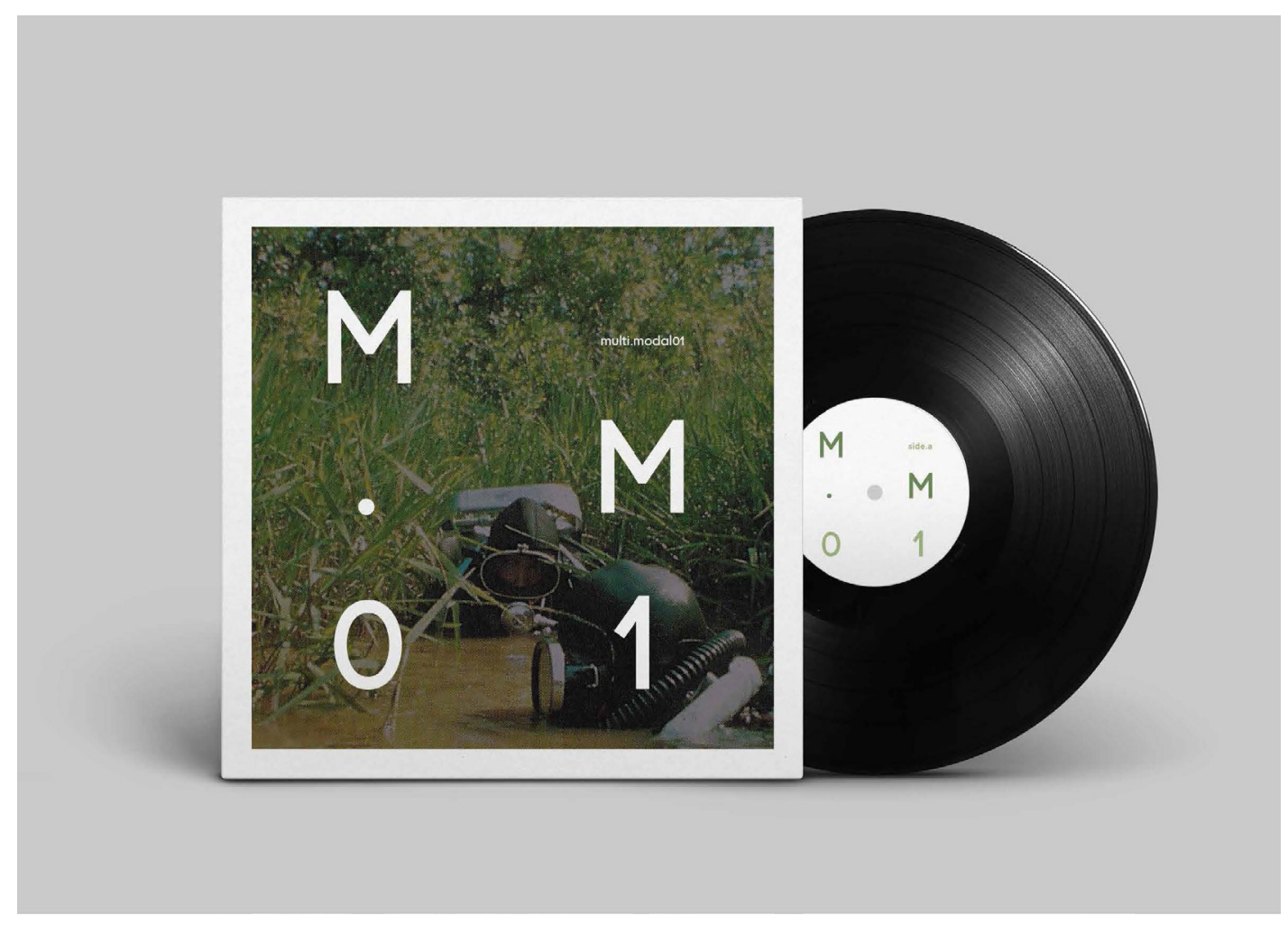

Decoys, Vinyl LP. Credit: multi.modal, 2018.

During our rehearsals in the field site of a studio, we experimented with and adapted the repertoire of historical Foley techniques. Our intention was to shadow the conventions of Foley in offering acoustic punctuations of events (such as the bear claw scrape or the rumble of thunder) against a backdrop of environmental atmosphere (the rain rendered by bacon sizzling) but it was our aim to shift from a natural to a post-natural register, one that considers the sustainability of sounding plastic as part of Foley's material heritage. Using our re-calibrated Foley techniques, we created a catalogue of post-natural events and atmospheres, according to a narrative logic that is only partially disclosed in the program note printed on an insert that comes with our multi.modal release and which culminates in the following two sentences from the liner notes: "The air churned in transmissions of static: weather turned metallic; teeth registered frequencies of the felt and uncertain. Here, high on the mountain we sat, attempting to decode its auditory particulates".

On the reverse of the LP insert is a visual score consisting of five components: five circles containing what might be identified as images captured through a microscope; sequences of letters and numbers, pairs of which appear to be affiliated with each of the circles; a line passing through the circles that could resembles a terrain profile; a horizontal stripe containing sliced sections of photographs depicting recognisable rock and foliage; a final intersected axis which, like the sliced photographs, seems to align with the labelled circles. 
The score was interpreted for Side B by Molitor and Rennie and Alison Blunt without any knowledge of the sound we had made. It functions as yet another inscription, a phonography without sound. The final two inscriptions presented below, re-write the material and performative modes that underscore the project. They perform another process of decoy and revelation and invite new translations of a Sonic Anthropocene. ${ }^{10}$
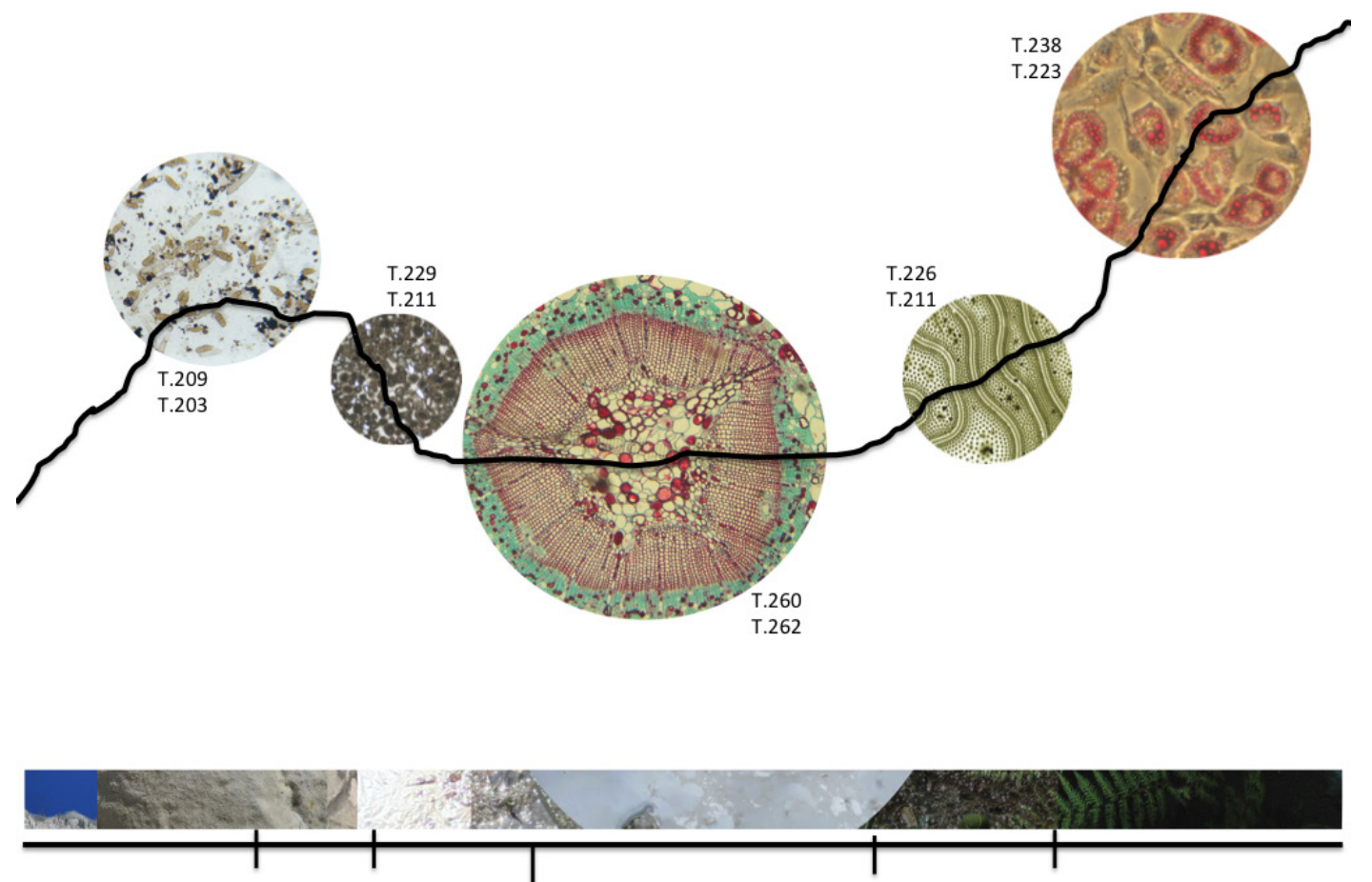

Decoys, score, inner sleeve of Vinyl LP. Credit: multi.modal, 2018

\section{MATERIAL INSCRIPTIONS}

\section{Metals}

With slim and sculpted sheets, sturdier cylinders (with welded handles) and fine filaments that are both stretched and wrapped, only the lustre is a clue to lead you back beneath the earth to origins in ores: to hematite, to cuprite, to milarite, and (especially) to bauxite. It is this same class of materials' magnetic and electrical qualities that enable the operations of the diverse devices that you will need to extract, securely store and then return vibrations to the air.

To agitate molecular motion into sound, you will rely on other characteristics than the ability to repel and attract flux lines and the capacity to conduct electricity. You will exploit

10 Link to LP: https://sparc.london/decoys. Link to Performance Event: https://iklectikartlab.com/decoysmulti-modal-01-lp-launch/ 
manufactured variations in firmness and flexibility in your collection of lustrous matter in order to orchestrate texture: to hear the reverberation of the hollow, the duller reports of the solid, to catch out loud the abrasions from this object and to listen to the smooth sibilants from that.

\section{Plastics}

Those devices that you will use to record and to playback? They also mould this next class of substances to their purposes. Again, the same polymers that sheath cables, that scaffold circuitry, that shield screens and that encase diaphragms, cones, coils and drives have also been shaped into everyday items that you can transform into sound. The palette of bright yellows, greens and pinks do not match lustre as a means to trace a genealogy back to geology, nor do the items' contours or consistencies readily suggest any origin in subterranean seams of crude oil, the cellulose of vegetal matter or the resins from plant exudations.

These objects, too, can be hollow and solid and sounded as such, but you can also set them to work to create crinkles, scratches and flutters, or to animate as audible the actions of stretching, squashing and rebounding.

\section{Compost, Decorative Stone, Woodchip}

This final group of makeshift sound-makers appears less cultivated than the other two; admittedly processed and packaged, but not as extensively so and very much more unlikely to have been involved in the manufacture of recording and reproduction devices (except, perhaps, as a cabinet for one of those cones).

Not to be approached as substitute instruments, this category becomes for you a medium to manipulate, something that is not to be struck or held like the matter from ores or from oils, but which itself holds: coating the whorls of your fingerprints, scratching your nails, sliding a splinter beneath the surface of your skin. When you add water, that medium becomes liquified and allows your hands to synthesise ripples and splashes, dribbles and drips. When you let an effervescent tablet sink and release its carbon dioxide, that medium becomes sporadically gaseous, hissing and fizzing, popping for your ears. 


\section{PERFORMATIVE INSCRIPTIONS}

\begin{tabular}{|c|c|c|c|c|}
\hline -FADE IN- & $\begin{array}{l}\text { Attach cassette } \\
\text { tape to fan and } \\
\text { turn on. }\end{array}$ & -CUT- & $\begin{array}{l}\text { Play with the } \\
\text { relations of air, } \\
\text { tape and } \\
\text { microphone. }\end{array}$ & $\begin{array}{l}\text { Petroleum based } \\
\text { plastic } \\
\text { encases sound } \\
\text { recording }\end{array}$ \\
\hline $\begin{array}{l}\text { Turn up the } \\
\text { gain. Find } \\
\text { thresholds of } \\
\text { material }\end{array}$ & & $\begin{array}{l}\text { Attach } \\
\text { electromagnetic } \\
\text { microphone to } \\
\text { fan. }\end{array}$ & & technologies. \\
\hline interactions. & $\begin{array}{l}\text { Move gloved } \\
\text { hands within a } \\
\text { bowl of mud } \\
\text { and gravel. }\end{array}$ & & $\begin{array}{l}\text { All recordings } \\
\text { are acts of } \\
\text { interpretation. }\end{array}$ & $\begin{array}{l}\text { Place woodchip } \\
\text { in metallic bowls } \\
\text { filled with water. } \\
\text { Drop Alka- } \\
\text { Seltzer into the }\end{array}$ \\
\hline $\begin{array}{l}\text { Foley is a decoy } \\
\text { practice that } \\
\text { fictions events }\end{array}$ & & $\begin{array}{l}\text { How can sound } \\
\text { fabricate new } \\
\text { ethical relations? }\end{array}$ & & liquid. Wait. \\
\hline and relations. & $\begin{array}{l}\text { Switch hands } \\
\text { into metallic } \\
\text { bowls filled } \\
\text { with nails and } \\
\text { screws. Move } \\
\text { gently. }\end{array}$ & & $\begin{array}{l}\text { Squeeze bubble } \\
\text { wrap. }\end{array}$ & $\begin{array}{l}\text { Continue to } \\
\text { move hands in } \\
\text { the mud and } \\
\text { gravel. }\end{array}$ \\
\hline $\begin{array}{l}\text { Flick water onto } \\
\text { hydrophone. }\end{array}$ & -CUT- & & $\begin{array}{l}\text { Play with the } \\
\text { relations of air, } \\
\text { foil and } \\
\text { microphone }\end{array}$ & $\begin{array}{l}\text { Who or what is } \\
\text { the author? }\end{array}$ \\
\hline $\begin{array}{l}\text { Compress } \\
\text { inflatable bed } \\
\text { foot pump. }\end{array}$ & $\begin{array}{l}\text { Foam is an } \\
\text { iceberg. }\end{array}$ & & & $\begin{array}{l}\text {-FADE } \\
\text { OUT- }\end{array}$ \\
\hline
\end{tabular}

\section{BIBLIOGRAPHY}

Carlyle, Angus \& Wright, Mark Peter. 2018. Decoys. (LP). London: Multi.modal.

Chakrabarty, Dipesh. 2009. "The Climate of History: Four Theses." Critical Inquiry 35 (2): 197-222.

.2018. “Anthropocene Time." History and Theory 57 (1): 5-32.

Earth Touch News Network: Available at <https://www.earthtouchnews.com/>.

Geertz, Clifford. 1973. The Interpretation of Cultures. New York: Basic Books.

Eley, Craig. 2012. "When it Rains it Pours," Smithsonian Folkways Magazine. Available at $<$ https://folkways.si.edu/magazine-fall-winter-2012-when-rains-pours-sounds-tropicalrain-forest-america-birth-science-series/nature-world/music/article/smithsonian>.

Ghosh, Amitav. 2016. The Great Derangement: Climate Change and the Unthinkable. Chicago \& London: University of Chicago Press.

Kanngieser, AM. 2015. “Geopolitics and the Anthropocene: Five Propositions for Sound," GeoHumanities 1 (1): 80-85. 
Mignolo, Walter. 2009. "Epistemic Disobedience, Independent Thought and Decolonial Freedom," Theory, Culture E Society 26 (7-8): 159-181.

Otolith Group. 2012. Medium Earth. (Film). London: LUX.

Sterne, Jonathan. 2003. The Audible Past: Cultural origins of sound reproduction. Durham, NC: Duke University Press.

Taussig, Michael. 2011. I Swear I Saw This: Drawings in Fieldwork Notebooks, Namely My Own. Chicago \& London: University of Chicago Press.

Theme Ament, Vanessa. 2014. Foley Grail: The Art of Performing Sound for Film, Games and Animation. New York \& London: Focal Press.

Wright, Mark Peter. 2017. "Postnatural Sound Arts". Journal of Sonic Studies 14. Available at $<$ https://www.researchcatalogue.net/view/292319/292320/0/0>.

Yusoff, Kathryn. 2013. "Geologic life: prehistory, climate, futures in the Anthropocene," Environment and Planning D: Society and Space 31 (5): 779 - 795.

.2017. "Epochal Aesthetics Affectual Infrastructure of the Anthropocene," Available at <http://www.e-flux.com/architecture/accumulation/121847/epochal-aesthetics-affectual-infrastructures-of-the-anthropocene/ $>$.

.2018. A Billion Black Anthropocenes or None. Minneapolis: University of Minnesota Press.

Date received: 2020-07-30

Date accepted: 2021-02-24 